Preprints of the

Max Planck Institute for

Research on Collective Goods

Bonn 2009/35

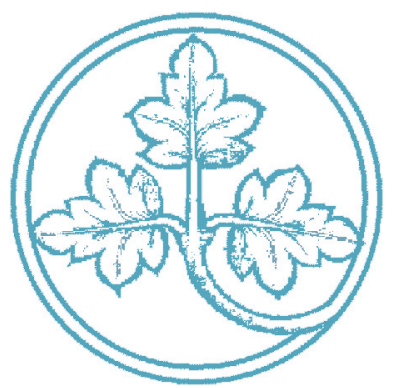

The Endowment Effect in

Groups with and without Strategic Incentives

Andreas Glöckner Janet Kleber

Stephan Tontrup

Stefan Bechtold

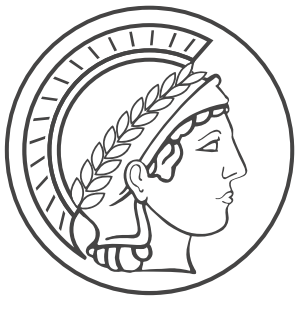




\section{The Endowment Effect in Groups with and without Strategic Incentives}

Andreas Glöckner / Janet Kleber / Stephan Tontrup / Stefan Bechtold

October 2009 


\title{
The Endowment Effect in Groups with and without Strategic Incentives ${ }^{\ddagger}$
}

\author{
Andreas Glöckner ${ }^{*}$ and Janet Kleber \\ Max Planck Institute for Research on Collective Goods, Bonn \\ Stephan Tontrup \\ Max Planck Institute for Economics, Jena
}

\&

\author{
Stefan Bechtold, \\ ETH Zurich
}

\begin{abstract}
The realization of market transactions often depends on decisions in groups in which members are anonymous and cannot communicate, but have interrelated outcomes. In a comprehensive study, we investigated the interaction of group effects, strategic effects and endowment effects in different group situations. We show that groups display an endowment effects for uncertain goods which is reduced by about $50 \%$ compared to the endowment effect in individuals in corresponding situations. In group situations with additional strategic incentives to overprice the endowment effect completely diminished. The strategic effects and group effects on pricing in group situations cannot be found for participants' personal valuations of the good, whereas the endowment effect for personal valuations prevailed in both group conditions. This indicates that the endowment effect might be more fundamental than group effects and strategic effects. A paramorphic model for pricing in strategic group situations is suggested and practical implications are discussed.
\end{abstract}

Keywords: Endowment Effects, Decision Making, Groups, Strategic Incentives

We thank Christoph Engel, Alexander Morell and Daniel Hawes for helpful suggestions and comments. Correspondence concerning this paper should be addressed to: Andreas Glöckner, Max Planck Institute for Research on Collective Goods, Kurt-Schumacher-Str. 10, D-53113 Bonn, Phone: +49-(0) 228 / 91416857 , E-mail: gloeckner@coll.mpg.de 


\section{Introduction}

Imagine a situation in which three persons own still unused technical patents and a pharmaceutical company suspects that the combination of these three patents could potentially lead to the development of an efficient medicine against a specific form of cancer. The company would certainly want to license the patents from the owners. Such a transaction would need an agreement of all owners to sell their patents at the bidding of the company. Whether this transaction takes place or not will depend on several factors. f crucial importance will be, of course, the valuation of the patents (i.e., expected profit) by the company as well as the valuation of the patents by the owners. Both valuations are highly uncertain because no specific probability is known whether the medicine that might emerge will be successful. Also, the validity and enforceability of patents is often difficult to determine ex ante (Lemley \& Shapiro, 2005). However, considering that people are not completely rational, valuations based on expectations might not be the only influences that matter. According to classic findings on endowment effects, it is reasonable to assume that owners have a (perhaps irrationally) increased valuation of their patents as measured by pricing decisions caused by the simple fact that they own them (Kahneman, Knetsch, \& Thaler, 1990, 1991).

Note, however, that the situation described above differs in some important ways from classic endowment studies, in which subjects are usually asked to buy (e.g., the company) or sell (e.g., the patent owner) objects by individual decision making. Here, the first major contrast is that the owners, although they might not know each other, act in a virtual group (see minimal group paradigm; Tajfel, 1970; Tajfel, Billig, Bundy, \& Flament, 1971) and their personal payoffs partially depend on the reactions of the other owners. Second, owners might also be aware that their own choices influence possible transactions and payments for the other owners and hence might harm them. Third, owners might act strategically to maximize their profit by asking for a price that exceeds their actual personal valuation of the patent. They may try to skim their share of the expected profit the pharmaceutical company might earn with the medicine. Hence it seems likely that endowment effects (i.e., increased valuation due to ownership), group effects (i.e., taking into account consequences for other group members), and strategic effects (i.e., overpricing due to individual incentives $)^{1}$ all influence the owners' pricing decisions while also affecting the likelihood of transactions; and thus benefits to society. Patent holders' strategic overpricing or increased valuation by the endowment effect might result in severe social welfare losses: A bundle of licenses will not be united in one hand so that crucial innovations will be harmed in the long run. An efficient cancer medicine might not be developed, since the company cannot afford to buy the necessary, but overpriced patents. Additionally, an immediate welfare loss results from the patents not being transferred to the party which actually values them most (Coase, 1960; for broad overviews, see Cooter \& Ulen, 2004; Sunstein, 2000).

1 Group effects and strategic effects are often related. In our study, however, we manipulate both independently. 
In this paper, we investigate the influence of group and strategic effects on the pricing of goods with uncertain payoffs (i.e., lottery tickets with unknown odds) with a special focus on how these effects influence the size of the endowment effect. A paramorphic model for the different influences on pricing is developed and tested.

\section{Endowment Effect: Findings and Explanations}

The endowment effect refers to the phenomenon that the minimum price at which a person agrees to sell a good (willingness to accept, WTA) exceeds her willingness to pay (WTP, the maximum price at which she agrees to buy it) for the same good (Kahneman et al., 1990, 1991). For pragmatic reasons (i.e., in avoiding that persons pay for goods from their own possibly limited money), in experimental studies the price at which a person is indifferent between a certain monetary value and the good (choosing value, $\mathrm{CV}$ ) is often used to measure endowment effects (e.g., Johnson, Häubl, \& Keinan, 2007). We also measure endowment effects by comparing subjects' CV and WTA.

Endowment effects seem to exist for a variety of objects, ranging from simple consumer goods (like mugs, pens, chocolate bars; e.g., Brown, 2005; Johnson, Häubl, \& Keinan, 2007; Nayakankuppam \& Mishra, 2005) to objects with risky or even uncertain outcomes such as lottery tickets (e.g., Cook \& Wu, 2001; Eisenberger \& Weber, 1995; Harless, 1989; Inder \& O'Brien, 2003; Knetsch \& Sinden, 1984; Peters, Slovic, \& Gregory, 2003; van de Ven, Zeelenberg, \& van Dijk, 2005; van Dijk \& van Knippenberg, 1996). The observed pricing pattern (i.e., higher WTA than CV than WTP) for these objects is usually the same, except for differences in magnitude (for an overview see Horowitz \& McConnell, 2002). Nevertheless, coming back to our introductory example, no studies are available that directly investigate the endowment effects for patents. Note, however, that patents share one crucial feature with lottery tickets: the value of both is usually highly uncertain. ${ }^{2}$ Therefore, in analogy, endowment effects for patents might be caused by similar cognitive mechanisms such as anticipated regret (see below).

\section{Explanations for endowment effects}

Several theories attempt to explain the endowment effect (for an overview, see Korobkin, 2003). Based on prospect theory (Kahneman \& Tversky, 1979), it has been argued that endowment effects result from the fact that losses loom larger than gains. Selling a good can be considered losing it. This loss must be compensated by a higher amount of money than the amount the person would be willing to invest in buying the good ("to gain it"). If the pricing decision is made under uncertainty, for instance by selling a lottery ticket or a patent, this effect might be fostered by the feeling of anticipated regret concerning foregone advantageous outcomes (Loomes \& Sugden, 1982). In line with this explanation, it was shown that the WTA is predominantly 
guided by anticipated negative feelings (such as regret), while anticipated positive feelings direct the WTP (Peters et al., 2003).

Along a different line of thought, query theory (Johnson et al., 2007) proposes that endowment effects result from differences in memory-retrieval processes being induced by the endowment state. According to this theory, the endowment state (i.e., whether a person owns a good or not) changes the way persons think about a possible trade. Decision makers decompose the question of how much money they are willing to buy or to sell a good for into a series of memory queries such as (1) "Why should I make the trade?" and (2) "Why should I not make the trade?". The former question retrieves value-decreasing aspects concerning the good arguing for the trade, while the latter retrieves value-increasing arguments suggesting not to trade. According to query theory, memory queries are ordered such that aspects speaking for the status quo are processed first, assigning larger weight to them in the process of value construction.

Finally, the more general parallel constraint satisfaction approach argues that pricing in market transactions is dependent on persons' mental representation of the situation and is particularly influenced by automatic bidirectional reasoning processes (Glöckner \& Betsch, 2008; Glöckner, Tontrup, \& Kleber, submitted; see also Holyoak \& Simon, 1999; Simon, Krawczyk, \& Holyoak, 2004). It is postulated that decision makers construct mental representations of decision problems and try to find the best and most consistent interpretation under parallel consideration of the pros and cons (i.e., constraints). The endowment state can influence people's construction of mental representation in different ways. Specifically, it has been argued that owners give more attention to the option they own. This leads to a stronger activation of this option compared to the alternative(s). Activation spreads from this option to related aspects. It increases the activation of supporting (positive) aspects and decreases the activation of contrary (negative) aspects. The resulting changes in the perception of positive and negative aspects (i.e., information distortions in the mental representation) cause endowment effects. It is assumed that further factors such as query order, regret, and loss aversion influence the construction of the mental representation as well. Hence, the parallel constraint satisfaction approach provides a very general framework to account for the different factors potentially causing endowment effects and their interplay.

\section{Endowment effects in groups}

Although the relative importance of the factors causing endowment effects is controversially debated, the effect in individuals can be considered a well-explored phenomenon. However, only little evidence concerning the prevalence and the size of endowment effects in group situations exists. In an early study using hypothetical goods, Carnevale (1995) extended the endowment effect to group-owned property in that two friends answered pricing questions together. In addition, this study examined the impact of cultural values (i.e., collectivism vs. individualism) on endowment effects. Carnevale found a group endowment effect for people with collectivist cultural values and not for individualists; whereas the endowment effect in individuals only occurred for individualists and not for collectivists. Independent of cultural values, the endowment 
effect was slightly higher in individuals than in groups. Unfortunately the author does not provide information as to whether the difference reached conventional significance levels. In a different study, Galin et al. (2006) investigated the effect of group negotiations on endowment effects, showing that negotiations within the group even increased the endowment effect. Nevertheless, no studies exist which investigate the endowment effect in group situations where subjects have to make separate pricing decisions that might influence other group members' outcome. Hence, from the scarce research on endowment effects in groups, no clear hypotheses can be derived for situations of group interaction such as the patent problem described in the introduction.

Evidence from general group research suggests that groups sometimes behave more rationally compared to individuals (for a critical overview, see Allen \& Hecht, 2004; Kerr, MacCoun, \& Kramer, 1996; Kerr \& Tindale, 2004). This could lead to smaller endowment effects in groups. However, findings concerning the "rationality of groups"-hypothesis are rather inconsistent. While some studies show an increase of rationality in groups (e.g., Bornstein \& Yaniv, 1998; Kocher \& Sutter, 2005), others have observed no differences (e.g., Fiegenbaum \& Thomas, 1988; Rockenbach, Sadrieh, \& Mathauschek, 2007; Sutter, 2007). Other studies even found the opposite effect in that individuals behave more rationally than groups (e.g., Cox \& Hayne, 2006; Paese, Bieser, \& Tubbs, 1993). Neither of these studies analyse the endowment effect, and their findings do not readily translate to our current framework. Therefore, no clear predictions concerning the size of the endowment effect in groups can be derived from general group research.

\section{Potential factors influencing the size of endowment effects in groups}

Due to this lack of empirical evidence, we derive predictions based on theoretical grounds. Considering the different factors that have been suggested as causes for the endowment effect, we expect that in groups the effect will be smaller than in individuals. The group situation should induce a different way to think about the decision situation which might a) reduce regret, b) change the order of memory queries, c) activate additional pro-social goals, and d) lead to a more objective mental representation of the trading/pricing decision. Concerning the first issue, the group situation could lead to reduced perceived responsibility (cf. Darley \& Latane, 1968) and, in turn, to reduced anticipated regret (Zeelenberg, van Dijk, \& Manstead, 1998). Persons in a group might feel less anticipated regret because they are not the only ones to risk missing a very advantageous pay-off. According to the anticipated regret explanation, this should reduce endowment effects. Furthermore, the group situation could induce a less strict order of memory queries. Persons might start thinking about the consequences of the group situation first instead of thinking about the status quo. According to the explanation given by the query theory, this should reduce the endowment effect as well. Also, the group situation could activate (consciously or unconsciously) pro-social goals, such as not to harm others through overpricing (Charness \& Jackson, 2007; see also Frey \& Meier, 2004). More generally, the group situation might induce people to think more broadly about the decision and might enhance their proclivity 
to include the other person's perspective into their individual considerations. This could lead to a less self-centered and thus more objective mental representation of the situation and to a more similar activation of the different options. According to the parallel constraint satisfaction approach, this should reduce endowment effects as well.

It is not immediately clear whether the effectiveness of an added incentive to strategically overprice should depend on the endowment state in the group setting. In principal, the added incentive could influence the price independent of people's valuation (hence, neutralizing the endowment effect), or it could lead to proportional increases in all pricing decisions; thus leaving the size of the endowment effect unchanged. For uncertain goods such as patents and lottery tickets, in which personal valuation is likely to be vague, we assume that strategic incentives have a high impact on pricing decisions (cf. anchoring effects; Whyte \& Sebenius, 1997). Hence, we start with the expectation that strategic incentive effects will prevail and will abolish the endowment effect.

\section{A Formalized Model for Pricing in Group Situations}

In this section, we develop a formal model of the relationship between the different components expected to influence pricing in group situations with strategic incentives. Let us denote $C V_{I}$ (choosing value) as the amount of money which makes a person indifferent if she has to choose between the money and a good (e.g., in a non-endowment condition). The minimum price an endowed person (individual, $I$ ) is willing to accept for selling the good $W T A_{I}$ can be written as:

$$
W T A_{I}=C V_{I}+E
$$

with $E$ indicating the individual endowment effect of the person for the good. According to the findings reported above it can be assumed that $E>0$. In a group situation as described in the introduction, additional group effects $G$ and effects of a strategic price $S$ have to be considered.

In the endowment condition, in a group situation without strategic incentives $(G n o S)$ an individual's willingness to accept $W T A_{G n o S}$ results from

$$
W T A_{\text {GnoS }}=C V_{I}+E G \text {. }
$$

As discussed above, we expect that the group situation should reduce the endowment effect, resulting in $0<G<1$. In a non-endowment condition, the choosing value in the same group situation $C V_{\text {GnoS }}$ should not be influenced by the group effect $G$ because no endowment effect exists (i.e., $E=0)$ :

$$
C V_{\text {GnoS }}=C V_{I} \text {. }
$$

In a group situation in which persons have the possibility to earn more money by overpricing (group with strategic incentive, GS), persons might be tempted to use this opportunity. The additional strategic incentive to overprice might either influence persons to add a specific value both to CV and WTA (i.e., add-on effect) or in that the strategic effect might completely determine 
the price; undermining endowment effects. For goods of highly uncertain value, we assume the latter (see above). Consequently, in a group situation with strategic incentives the individual's willingness to accept $W T A_{G S}$ should be equal to the choosing value in the same group situation $C V_{G S}$ because both merely reflect the strategic price $S$ :

$W T A_{G S}=C V_{G S}=S$.

In the study reported below, we tested specific hypotheses underlying this (paramorphic) model for pricing in group situations by independently manipulating endowment state and group situations. We used a standard individual endowment paradigm as control condition and compared it with two group conditions (with and without an incentive to overprice).

\section{Hypotheses}

Based on the theoretical arguments and the resulting paramorphic model presented in the previous section, we expect that individuals' pricing will be influenced by both a mere effect of deciding in an anonymous group and by adding a strategic incentive to overprice. We expected a reduction of the endowment effect in the group condition for the different reasons discussed above $\left(\mathrm{H}_{1}\right)$. It might, for instance, induce thinking about the different lottery tickets from a less personal and hence more objective perspective. For the group condition with additional strategic incentive, we expect persons to be selfish and to indicate a price that does not reflect their valuation but was driven by the strategic price (i.e., S) given in the endowment condition as well as in the non-endowment condition. Hence, the endowment effect should disappear for persons pricing the lottery ticket $\left(\mathrm{H}_{2}\right)$. In contrast, we expected no effect of both the group and the incentive manipulation on the real personal valuation of the lottery ticket (i.e., valuation without considering the group situation) indicating that group effects and incentive effects only influence persons' transaction pricing, but do not change their real valuation of the object $\left(\mathrm{H}_{3}\right)$.

\section{Method}

Participants and design. One hundred and eighteen volunteers (79 female, mean age: 24.8 years) participated in the experiment and were rewarded with a show-up fee of 12 Euros per hour. Depending on their responses, they could receive an additional amount of money between 0.25 Euro and 10 Euros or 25 Euros if they drew a winning lottery ticket. We used a 2 (endowment state) $\mathrm{x} 3$ (group situation) between-subjects design that varied the endowment state across three levels of group condition (details see below): a control condition in which participants decided alone (single condition); a group situation in which three participants who did not know each other's identity interactively determined the outcome (basic group condition); finally a strategic group situation, in which we implemented an additional strategic incentive for participants to overprice the lottery ticket (group+incentive condition). The experiment was run in sessions of 6 to 12 persons. In the two group conditions, three participants with the same endowment state 
were randomly assigned to each of the groups. In all four group conditions members could not identify one another and were not able to communicate. Participants were recruited from the Max Planck subjects pool in Bonn using the Orsee system (Greiner, 2004).

Participants were randomly assigned to one of the six conditions and then informed about the lottery (i.e., a transparent urn with lottery tickets) from which they could possibly draw a ticket. To induce uncertainty about the expected value of the lottery, participants were informed about the number of winning tickets in the urn (i.e., 10) with a value of 25 Euros, but they did not receive exact information about the blanks. They could, however, get a rough estimation of the winning probability by looking at the transparent urn which allowed an estimation of the total number of tickets. Hence, participants could roughly estimate, but not calculate exactly, the expected utility of the lottery. The actual number of non-winning tickets was 40, so the expected value over all tickets in the lottery was 5 Euros.

Procedure. Figure 1 gives a brief overview of the general procedure. The experiment started with a manipulation of the endowment state in that half of the participants drew a closed lottery ticket and the other half did not. Participants were then randomly assigned to one of the three group conditions giving them different instructions concerning the market rules for trading the lottery tickets. They were asked to make binding price decisions for trading the lottery tickets using a Becker, DeGroot and Marschak mechanism (1964, details see below). Additionally, participants indicated their personal valuation of the ticket and their expectations how other group members (or, in the single condition, other participants) would price the tickets. The personal valuation aimed at measuring individuals' pricing in the absence of group effects and strategic effects. Finally, the real market transactions were implemented, and participants answered control questions to guarantee their understanding of the procedure. Participants who kept (or received) a lottery ticket opened it. 25 Euros were added to the payment of the winning subjects, while the others received no additional payment. Participants who sold the lottery ticket (or received the money) were paid for trading the lottery tickets in accordance with the market rules.

Figure 1. Overview of Procedure

\begin{tabular}{|c|c|c|c|c|}
\hline \multicolumn{5}{|l|}{ Time } \\
\hline $\begin{array}{c}\text { Endowment } \\
\text { manipulation: } \\
\text { endowment vs. } \\
\text { non- } \\
\text { endowment }\end{array}$ & $\begin{array}{l}\text { Group } \\
\text { manipulation: } \\
\text { Single vs. } \\
\text { Group vs. } \\
\text { Group+Incent. }\end{array}$ & $\begin{array}{l}\text { BDM pricing: } \\
\text { binding deci- } \\
\text { sion for all } \\
\text { possible offer } \\
\text { prices }\end{array}$ & $\begin{array}{l}\text { Personal valua- } \\
\text { tion, expected } \\
\text { pricing of others, } \\
\text { control ques- } \\
\text { tions }\end{array}$ & $\begin{array}{l}\text { Offer price } \\
\text { drawn and } \\
\text { transaction im- } \\
\text { plemented }\end{array}$ \\
\hline
\end{tabular}

In the endowment conditions, every participant took one lottery ticket with the request not to open it, whereas in contrast in the non-endowment conditions the lottery tickets were only shown, but not given to the participants. In the endowment conditions participants had the opportunity to sell or keep their ticket, while in the non-endowment conditions they were asked to choose between an amount of money and the lottery ticket. 
In the single condition, participants sold their lottery ticket (endowed) or received a lottery ticket (not endowed) if they personally accepted an external price offer (for details, see below). Group conditions (basic group and group+incentive) were subject to different market rules for trading lottery tickets. In both group conditions, participants played together with two other anonymous individuals subject to the same market rules. In the basic group condition, the situation was constructed so that persons had no strategic incentive to overprice. The offer price was compared to the highest of the three prices requested by all members of the group. If all group members agreed to accept the offer to sell their ticket (or, in the non-endowment condition, chose the money) at the amount which was offered, the group transaction took place. Otherwise, all kept their lottery ticket (or, in the non-endowment condition, got the lottery ticket). Note that, under such conditions, overpricing is irrational because all group members receive the same offered price and not a possibly increased price they could request otherwise. In the group+incentive condition, this was different. The group received a total price offer for all three lottery tickets combined. If the offer was equal to or higher than the sum of the prices requested by the three persons, the transaction took place and each person received the money she requested. Otherwise, all persons kept (or, in the non-endowment condition, received) the lottery ticket. In this group+incentive condition, persons had a strategic incentive to overprice because each person could maximize her individual profit by stating a price higher than their real valuation (i.e., defecting). This was individually beneficial if the overall price was still higher than the sum of the requested prices. Then the participant received a selling price for the ticket higher than his or her real valuation was. Therefore for any price above their personal valuation participants were facing a trade-off between increasing the probability of their team selling (receiving) the ticket and extracting a lot of money from the transaction in case it took place. On the other hand, if subjects overpriced, the transaction could fail, leading to losses (or foregone wins) even though the sum of their true valuations was actually lower than the offer price (cf. prisoner's dilemma situation).

We used a modified version of a BDM (Becker et al., 1964) mechanism to elicit preferences. Persons a priori determined their decisions for all possible offer prices. Later on, the actual offer price was randomly drawn. In the single condition, we used the standard BDM procedure, in which participants made binding decisions for all monetary values from 0.25 Euro to 10 Euros in steps of 25 Cent to sell or keep the ticket (endowment condition) or to choose the money over the ticket or the ticket over the money (non-endowment condition). In the basic group condition, essentially the same procedure was used except that the offer price was compared to all three individual decisions for this offer price. If all members of the group indicated to sell their ticket (vs., in the non-endowment condition, preferred the money over the ticket) for this price, all of them got the drawn offer price and the transactions took place. Otherwise, if at least one member of the group was not willing to trade for the given price (vs., in the non-endowment condition, preferred the ticket over the money), all three members had to keep their ticket (vs., in the nonendowment condition, got a lottery ticket). In the group+incentive condition, an overall offer price for the group was drawn from all possible prices that could result from summing individuals' prices (i.e., 0.75 Euro to 30 Euros). In this condition, the lowest prices for which the group members wanted to sell their ticket (vs., in the non-endowment condition, they preferred to take 
the money instead of the ticket) were determined and the sum of these prices was compared to the total offer price. If the sum was below or equal to this offer price, each of them received their minimum accepted price (vs., in the non-endowment condition, the lowest amount of money for which they preferred to take the money instead of the ticket). Otherwise, all three kept the lottery ticket (vs., in the non-endowment condition, received a lottery ticket).

\section{Results}

We tested whether participants understood the instructions by analyzing their answers to the control questions. The results revealed that 21 of the participants answered at least one of the questions incompletely. These participants were excluded from our analyses. ${ }^{3}$

In line with $\mathrm{H}_{1}$, which states that the endowment effect for BDM prices (endowment condition: WTA, non-endowment condition: CV) should be smaller for anonymous group situations, we observed an interaction for endowment state with group condition (Figure 2, left). A strong endowment effect was observed for the single condition, whereas the effect was smaller in the basic group condition and disappeared completely in the group+incentive condition. To test our first hypothesis statistically, we conducted a regression of predicting price $\left(W T A_{I} / C V_{I}\right)$ on endowment state, our manipulation of group situations (i.e., dummy codes for basic group and group+incentive), and their interaction (Table 1, column 1). The interaction between (basic) group and endowment state turned out to be significant supporting $\mathrm{H}_{1}$.

A $t$-test revealed that the endowment effect was still significant in the basic group condition, even though reduced, $t(29)=1.74, p=.046, d=0.65$ (one-tailed). In line with $\mathrm{H}_{2}$, however, the effect disappeared in the group+incentive condition, $t(28)=0.27, p=.39, d=0.10$ (one-tailed, see also the strong interaction effect of endowment and group+incentive in Table 1). In the regression, we also found the expected additional main effect for the group+incentive condition (i.e., significant group+incentive dummy), indicating that the strategic incentive led to an overall increase in pricing (i.e., general overpricing).

Our third hypothesis stated that, in contrast to the findings for BDM pricing, the manipulations of group and strategic incentives should have no effect on personal valuations of the lottery ticket. The personal valuation was measured using an open answering format (i.e., indicating a price), which produced four extreme outliers $(M+/-3 S E)$ that were excluded from the analysis. We found again a strong endowment effect, but in line with $\mathrm{H}_{3}$, this effect did not differ between the group conditions (Figure 2, right). To test $\mathrm{H}_{3}$ statistically, we regressed the personal valuation on endowment state, dummy variables for group situations and their interaction (Table 1, column 2). As we predicted, the main effect for both group condition dummies as well as their interactions with endowment state were far from significant. 
Table 1: Overall regression table of dependent variables

\begin{tabular}{|c|c|c|c|c|}
\hline & $\begin{array}{c}(1) \\
\text { BDM price }\end{array}$ & $\begin{array}{c}\text { (2) } \\
\text { Personal } \\
\text { Valuation }\end{array}$ & $\begin{array}{c}(3) \\
\text { Difference }\end{array}$ & $\begin{array}{c}\quad(4) \\
\text { Expectation } \\
\text { Price others }\end{array}$ \\
\hline $\begin{array}{l}\text { Endowment } \\
\text { (1=yes, } 0=\text { no) }\end{array}$ & $\begin{array}{l}2.918^{* * *} \\
(4.27)\end{array}$ & $\begin{array}{l}3.298^{* * *} \\
(3.54)\end{array}$ & $\begin{array}{l}-0.971 \\
(-1.16)\end{array}$ & $\begin{array}{c}2.582^{* * *} \\
(3.60)\end{array}$ \\
\hline $\begin{array}{l}\text { (Basic) Group } \\
(1=y e s, 0=\text { no) }\end{array}$ & $\begin{array}{l}0.364 \\
(0.66)\end{array}$ & $\begin{array}{l}0.417 \\
(0.81)\end{array}$ & $\begin{array}{l}-0.0533 \\
(-0.09)\end{array}$ & $\begin{array}{l}-0.158 \\
(-0.28)\end{array}$ \\
\hline $\begin{array}{c}\text { Group+Incentive } \\
(1=\text { yes, } 0=\text { no })\end{array}$ & $\begin{array}{l}1.911^{* *} \\
(3.07)\end{array}$ & $\begin{array}{l}0.826 \\
(1.22)\end{array}$ & $\begin{array}{l}1.083 \\
(1.58)\end{array}$ & $\begin{array}{l}1.094^{*} \\
(2.32)\end{array}$ \\
\hline Endowment ${ }^{\star}$ Group & $\begin{array}{l}-1.914^{*} \\
(-2.15)\end{array}$ & $\begin{array}{l}0.0745 \\
(0.06)\end{array}$ & $\begin{array}{l}-1.398 \\
(-1.18)\end{array}$ & $\begin{array}{l}-1.572 \\
(-1.68)\end{array}$ \\
\hline $\begin{array}{l}\text { Endowment* } \\
\text { Group+Incentive }\end{array}$ & $\begin{array}{l}-2.749^{* *} \\
(-2.98)\end{array}$ & $\begin{array}{l}0.189 \\
(0.16)\end{array}$ & $\begin{array}{l}-2.346^{*} \\
(-2.01)\end{array}$ & $\begin{array}{l}-1.420 \\
(-1.51)\end{array}$ \\
\hline Constant & $\begin{array}{l}4.069^{* * *} \\
(10.79)\end{array}$ & $\begin{array}{l}3.319^{* * *} \\
(10.28)\end{array}$ & $\begin{array}{l}0.750^{*} \\
(2.39)\end{array}$ & $\begin{array}{l}4.444^{* * *} \\
(13.01)\end{array}$ \\
\hline Observations & 97 & 93 & 93 & 96 \\
\hline Adjusted $R^{2}$ & 0.218 & 0.316 & 0.180 & 0.209 \\
\hline
\end{tabular}

Note. Values refer to unstandardized regression weights. The $t$ statistics are given in parentheses. Significance levels are indicated by ${ }^{*} p<0.05,{ }^{* *} p<0.01,{ }^{* * *} p<0.001$. 
Figure 2. BDM price and personal valuation by endowment state and group condition. Error bars indicate SEs.
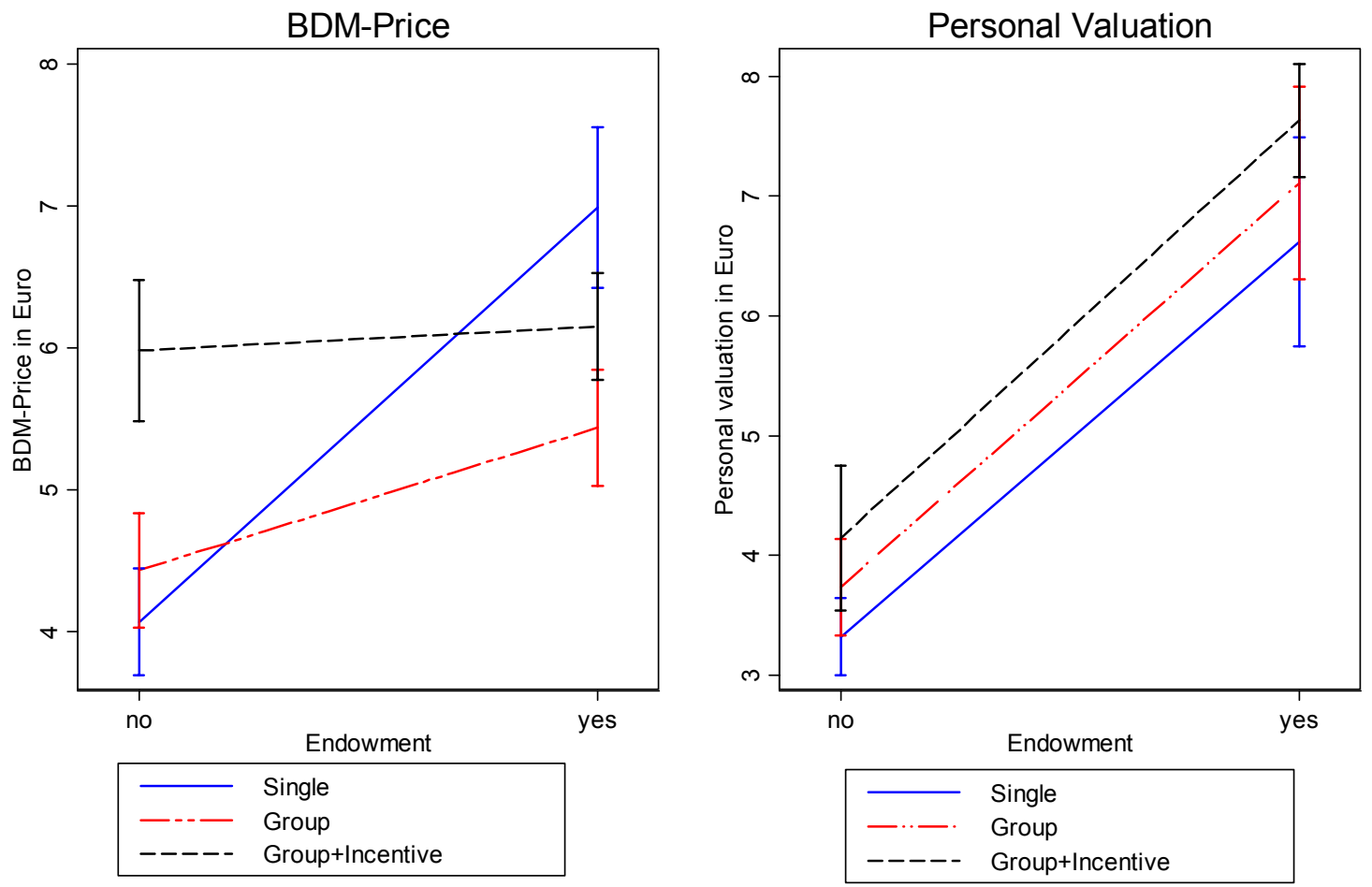

To further analyze the different effects of our manipulation on price, we calculated a difference score subtracting personal valuation from the BDM price. Positive values indicate strategic overpricing whereas negative values indicate underpricing. The difference score was regressed on our manipulated factors (Table 1, column 3). The interaction between group+incentive condition and endowment state turned out to be significant. This indicates large differences between BDM pricing and personal valuations in the group+incentive condition (Figure 3, left), whereas in the single condition, almost no deviations were observed. In the group+incentive condition, participants set prices below their own personal valuations when endowed, but overpriced when not endowed. 
Figure 3. Difference BDM price and valuation and expected pricing of others by endowment state and group condition. Error bars indicate SEs.
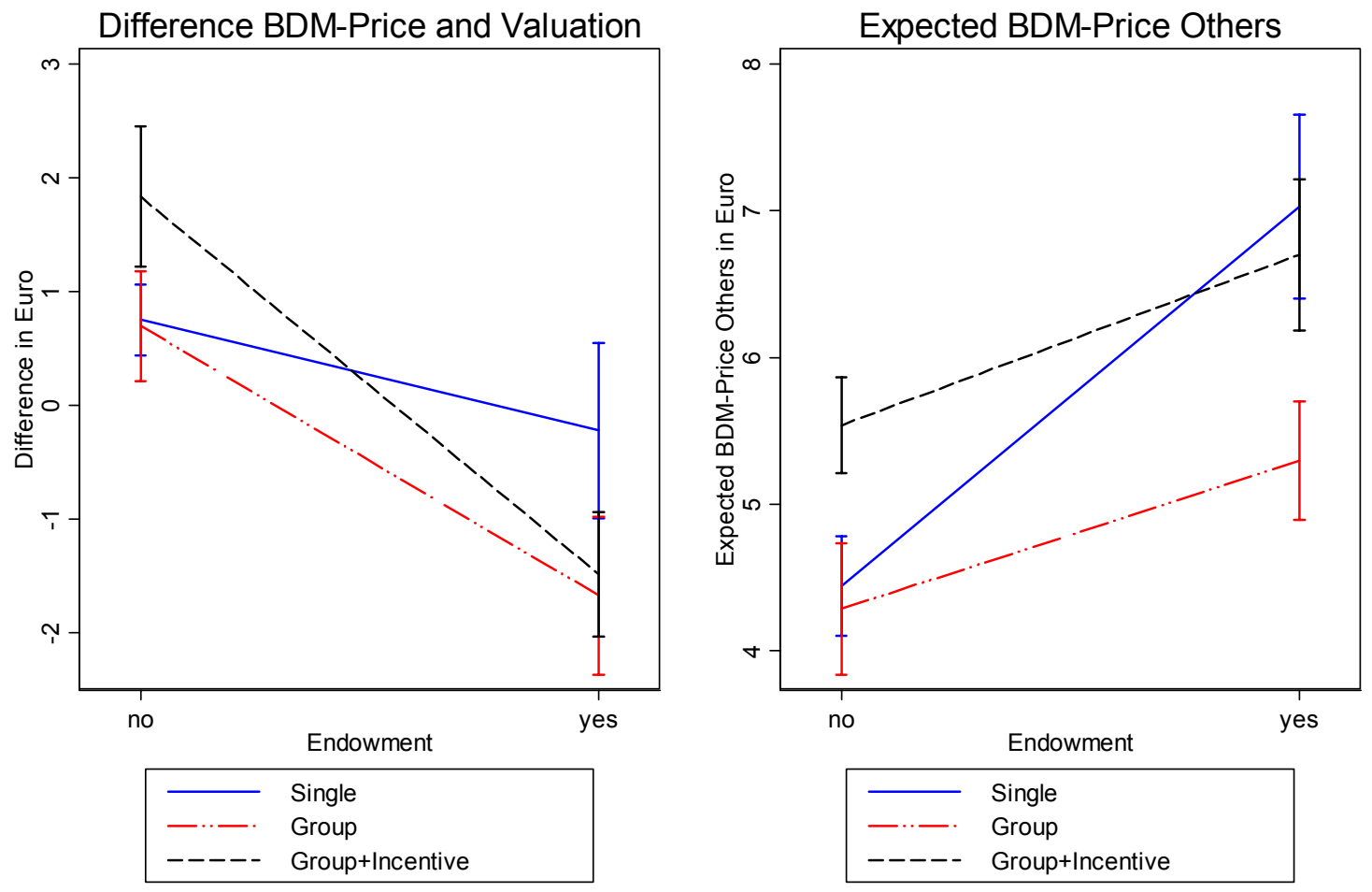

For a deeper exploratory analysis of the processes underlying BDM pricing, we investigated participants' beliefs of other people's BDM pricing, regressing it on our manipulated factors (Table 1, column 4). We observed a main effect for endowment state and group+incentive condition, indicating that persons anticipate strategic as well as endowment-based overpricing. Although the two interactions did not reach conventional significance levels, they tend to be in the same directions as the interactions for BDM pricing (cf. Table 1, column 1). This might indicate that persons (perhaps implicitly) generalize from their own price to their expectation of others' pricing decisions; suggesting a false-consensus effect (Ross, Greene, \& House, 1977). Interestingly, the correlation between BDM prices and beliefs about others' pricing decisions $(r=.55, p<.001)$ and the correlation between personal valuation and beliefs $(r=.64, p<.001)$ were both highly significant, with the latter being slightly stronger. Hence, it seems that persons form their beliefs by generalizing not only from their personal valuation, but also in addition, seem to take into account the group and strategic factors that influence their own BDM pricing.

Overall, the data fit nicely to the (paramorphic) model concerning pricing in strategic group situations, proposed in equations 1 to 4 . The prediction of the model for BDM pricing using the best estimates for the variables CV, E, S, and G is presented in Figure 4. The predicted pattern nicely matches the observed date (Figure 2, left). 
Figure 4. Predictions of the model for pricing in strategic group situations. The relative size of the variables is based on fitting to the observed data $\left(C V_{l}=4.27\right.$ Euros, $E=2.92$ Euros, $S=6.13$ Euros and $G=0.48)$.

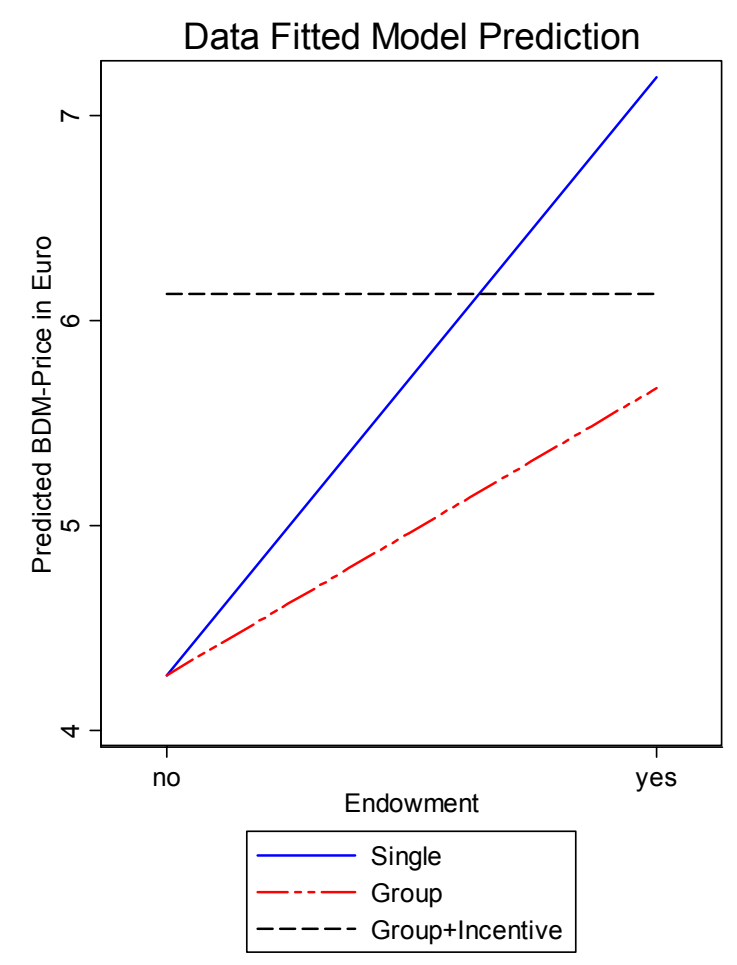

\section{Rationality Analysis}

The true expected value of the lottery ticket was 5 Euros. Participants did not know this expected value, but they could generate an informed guess based on their estimation of the number of nonwinning lottery tickets in the transparent urn (see above). Hence, for risk-neutral people it would have been rational to select this price as WTA or CV. Due to the fact that most persons are riskaverse, whereas only a negligible proportion is risk-seeking (Holt \& Laury, 2002), the prices indicated by subjects should even be lower. In contrast to this prediction, we only observed average prices below this 5-Euro benchmark in the non-endowment conditions for individuals and groups without incentives (Figure 2, left). In all other conditions, we found overpricing with respect to our rationality prediction. Overpricing is strongest in the individual condition with endowment. A one sample $t$-test against the expected value (i.e., 5 Euros) reveals a significant overpricing effect, $t(19)=3.51, p=.002, d=0.37$ (two-tailed). In the group+incentive condition, pricing significantly above 5 Euros was also found; irrespective of the endowment state (endowment: $t(14)=3.06, p=.009, d=0.44$, two-tailed; non-endowment: $t(13)=2.25, p=.042, d=0.35$, two-tailed). For endowed participants in the basic group condition, we also observed a tendency towards irrational overpricing that was, however, not significantly higher than 5 Euros, $t(15)=1.07, p=.303, d=0.14$ (two-tailed). Hence, mainly non-endowed subjects and groups without strategic incentives seem to behave rationally with respect to the expected value of the lottery ticket. 


\section{Discussion}

In the current study, we investigated endowment effects in group situations with and without strategic incentives. On theoretical grounds, we first developed a paramorphic model for pricing in such situations which takes into account endowment effects, group effects, and strategic effects. The model is based on the assumption that endowment effects for goods with uncertain value are reduced in group situations as compared to individual situations and that endowment effects disappear if strategic incentives to overprice exist. Both assumptions were supported by the data. In our study, the mere group effect reduced the endowment effect by about $50 \%$ compared to the individual situation. Furthermore, we found that participants' personal valuation of the good was influenced by the endowment effect, but not by the strategic and the group effect. This might indicate that endowment effects are more fundamental and are only modified later on by group effects and strategic effects. Finally, our findings might indicate that persons' beliefs concerning the pricing decisions of the other group members were driven by both their own personal valuation of the tickets but also by anticipating group and strategic effects.

\section{Practical Implications}

Compared to the expected value of the lottery ticket, the results show a general tendency to overprice due to both endowment effects and strategic effects. For the transaction described in our introductory example and similar market situations, this suggests welfare losses for society. The resulting regulatory problem is intricate. Strategic incentives lead to overpricing, but they seem at least to reduce the endowment effect. Thus, solely eliminating the strategic incentives would strengthen the impact of the endowment effect in group situations, which would again lead to overpricing - only for different reasons. Therefore, it is not sufficient to design transaction rules that eliminate strategic incentives to overprice, but intervention needs to additionally target the endowment effect. One possibility might be to use a specific query order instruction as suggested by Johnson et al. (2007; see also Glöckner et al., submitted). The influence of the endowment effect on their trading decision might be explained to the patent owners by instructing them to think thoroughly about the advantages of a transaction. Nevertheless, one has to be aware that these instructions will have an impact on the distribution of the gains from trade between owners and buyers (e.g., it might weaken the sellers' position in the negotiation). Thus any intervention has to take aspects of distributional fairness into account.

\section{Limitations}

The model we suggested does not aim to describe processes. It was designed to capture the relative influence of different factors in strategic group situations. Further research will be necessary to explore its' parameters, their stability, and of course also the underlying processes in more detail. 
Recent findings from our group indicate, for instance, that the overall pattern of results might depend on the nature of the good that is traded. In a study using goods with real values (i.e., coffee mugs) we observed pricing decisions more in line with "add-on effects" (Tontrup, Bechtold, \& Glöckner, in preparation): participants did not move their WTA/CV to the strategic price, but seemed to add a strategic premium to their personal valuation of the good. This difference might be explained by the different reasons for the emergence of endowment effects in traditional goods (i.e., coffee mugs) and uncertain goods (i.e., lottery tickets and patents).

Furthermore, in our experiment persons interacted in virtual groups, under strict anonymity and without being able to communicate. Considering the study by Galin et al. (2006), which concludes that discussion in groups increases endowment effects, our model could be extended or modified for group situations with direct interaction.

As we aimed to illustrate in the introductory example, efficient transactions in group situations with strategic incentives are of high importance for society. In this paper, we provide results that allow a more differentiated view on the interaction of overpricing incentives, group effects, and endowment effects in bargaining situations, which might help to reduce welfare losses for society. 


\section{References}

Allen, N. J., \& Hecht, T. D. (2004). The 'romance of teams': Toward an understanding of its psychological underpinnings and implications. Journal of Occupational and Organizational Psychology, 77, 439-461.

Becker, G. M., DeGroot, M. H., \& Marschak, J. (1964). Measuring utility by a single-response sequential method. Behavioral Science, 9, 226-232.

Bornstein, G., \& Yaniv, I. (1998). Individual and group behavior in the ultimatum game: Are groups more "rational" players? Experimental Economics, 1(1), 101-108.

Carnevale, P. J. (1995). Property, culture, and negotiation. In R. Kramer \& D. M. Messick (Eds.), Negotiation as a social process (pp. 309-323). Newbury Park, CA: Sage Publications.

Charness, G., \& Jackson, M. O. (2007). The role of responsibility in strategic risk-taking [Electronic Version], from http://ssrn.com/paper=937034

Coase, R. (1960). The problem of social cost. Journal of Law and Economics, 3, 1-44.

Cook, H., \& Wu, A. (2001). On the valuation of goods and selection of the best design alternative. Research in Engineering Design, 13(1), $42-54$.

Cooter, R., \& Ulen, T. (2004). Law and Economics. Boston: Addison Wesley Longman.

Cox, J. C., \& Hayne, S. C. (2006). Barking up the right tree: Are small groups rational agents? Experimental Economics, 9(3), 209-222.

Darley, J. M., \& Latane, B. (1968). Bystander intervention in emergencies: Diffusion of responsibility. Journal of Personality and Social Psychology, 8(4), 377-383.

Eisenberger, R., \& Weber, M. (1995). Willingness-to-pay and willingness-to-accept for risky and ambiguous lotteries. Journal of Risk and Uncertainty, 10(3), 223-233.

Fiegenbaum, A., \& Thomas, H. (1988). Attitudes toward risk and the risk-return paradox: Prospect Theory explanations. Academy of Management Journal, 31(1), 85-106.

Frey, B., \& Meier, S. (2004). Social comparisons and pro-social behavior: Testing "conditional cooperation" in a field experiment. American Economic Review, 94, 1717-1722.

Galin, A., Gross, M., Kella-Egozy, I., \& Sapir, S. (2006). The endowment effect in individual and team negotiations. Tel Aviv University, Faculty of Management.

Glöckner, A., \& Betsch, T. (2008). Modeling option and strategy choices with connectionist networks: Towards an integrative model of automatic and deliberate decision making. Judgment and Decision Making, 3(3), 215-228. 
Glöckner, A., Tontrup, S., \& Kleber, J. (submitted). Investigating the query theory for value construction: Endowment effects are caused by bidirectional activation instead of query order.Unpublished manuscript, Manuscript submitted for publication.

Greiner, B. (2004). An Online Recruitment System for Economic Experiments. In K. Kremer \& V. Macho (Eds.), Forschung und wissenschaftliches Rechnen 2003. GWDG Bericht 63 (pp. 79-93). Göttingen: Ges. für Wiss. Datenverarbeitung.

Harless, D. W. (1989). More laboratory evidence on the disparity between willingness to pay and compensation demanded Journal of Economic Behavior \& Organization, 11(3), 359-379.

Holt, C. A., \& Laury, S. K. (2002). Risk aversion and incentive effects. American Economic Review, 92(5), 1644-1655.

Holyoak, K. J., \& Simon, D. (1999). Bidirectional reasoning in decision making by constraint satisfaction. Journal of Experimental Psychology: General, 128(1), 3-31.

Horowitz, J. K., \& McConnell, K. E. (2002). A review of WTA/WTP studies. Journal of Environmental Economics and Management, 44(3), 426-447.

Inder, B., \& O'Brien, T. (2003). The Endowment Effect and the Role of Uncertainty. Bulletin of Economic Research, 55(3), 289-301.

Johnson, E. J., Häubl, G., \& Keinan, A. (2007). Aspects of endowment: A query theory of value construction. Journal of Experimental Psychology: Learning, Memory, and Cognition, $33(3), 461-474$.

Kahneman, D., Knetsch, J. L., \& Thaler, R. H. (1990). Experimental tests of the endowment effect and the Coase theorem. Journal of Political Economy, 98, 1325-1348.

Kahneman, D., Knetsch, J. L., \& Thaler, R. H. (1991). Anomalies: The endowment effect, loss aversion, and status-quo bias. Journal of Economic Perspectives, 5(1), 193-206.

Kahneman, D., \& Tversky, A. (1979). Prospect theory: An analysis of decision under risk. Econometrica, 47, 263-292.

Kerr, N. L., MacCoun, R. J., \& Kramer, G. P. (1996). Bias in judgment: Comparing individuals and groups. Psychological Review, 103(4), 687-719.

Kerr, N. L., \& Tindale, R. S. (2004). Group performance and decision making. Annual Review of Psychology, 55, 623-655.

Knetsch, J., \& Sinden, J. (1984). Willingness to Pay and Compensation Demanded: Experimental Evidence of an Unexpected Disparity in Measures of Value. Quarterly Journal of Economics, 99(3), 507-521. 
Kocher, M. G., \& Sutter, M. (2005). The decision maker matters: Individual versus group behaviour in experimental beauty-contest games. Economic Journal, 115(500), 200-223.

Korobkin, R. (2003). The endowment effect and legal analysis. Northwestern University Law Review, 97(3), 1227-1293.

Lemley, M. A., \& Shapiro, C. (2005). Probabilistic patents. Journal of Economic Perspectives, 19(2), 75-98.

Loomes, G., \& Sugden, R. (1982). Regret theory: An alternative theory of rational choice under uncertainty. Economic Journal, 92(368), 805-824.

Paese, P., Bieser, M., \& Tubbs, M. (1993). Framing effects and choice shifts in group decision making. Organizational Behavior and Human Decision Processes, 56, 149-149.

Peters, E., Slovic, P., \& Gregory, R. (2003). The Role of Affect in the WTA/WTP Disparity. Journal of Behavioral Decision Making, 16(4), 309.

Rockenbach, B., Sadrieh, A., \& Mathauschek, B. (2007). Teams take the better risks. Journal of Economic Behavior \& Organization, 63(3), 412-422.

Ross, L., Greene, D., \& House, P. (1977). The false consensus effect: An egocentric bias in social perception and attribution processes. Journal of Experimental Social Psychology, 13(3), 279-301.

Simon, D., Krawczyk, D. C., \& Holyoak, K. J. (2004). Construction of preferences by constraint satisfaction. Psychological Science, 15(5), 331-336.

Sunstein, C. R. (Ed.). (2000). Behavioral law and economics. Cambridge, UK: Cambridge University Press.

Sutter, M. (2007). Are teams prone to myopic loss aversion? An experimental study on individual versus team investment behavior. Economics Letters, 97(2), 128-132.

Tajfel, H. (1970). Experiments in intergroup discrimination. Scientific American, 223(5), 96-102.

Tajfel, H., Billig, M. G., Bundy, R. P., \& Flament, C. (1971). Social categorization and intergroup behavior. European Journal of Social Psychology, 1(2), 149-177.

van de Ven, N., Zeelenberg, M., \& van Dijk, E. (2005). Buying and selling exchange goods: Outcome information, curiosity and the endowment effect. Journal of Economic Psychology, 26(3), 459-468.

van Dijk, E., \& van Knippenberg, D. (1996). Buying and selling exchange goods: Loss aversion and the endowment effect. Journal of Economic Psychology, 17(4), 517-524. 
Whyte, G., \& Sebenius, J. K. (1997). The effect of multiple anchors on anchoring in individual and group judgment. Organizational Behavior and Human Decision Processes, 69(1), 75 85.

Zeelenberg, M., van Dijk, W., \& Manstead, A. (1998). Reconsidering the Relation between Regret and Responsibility. Organizational Behavior and Human Decision Processes, 74(3), 254-272. 


\section{Preprints 2009}

2009/34: Lehmann, S., The German elections in the 1870s: why Germany turned from liberalism to protectionism

forthcoming in: Journal of Economic History, In Press.

2009/33: Hakenes H., Schnabel I., Credit Risk Transfer and Bank Competition

2009/32: Jansen J., Beyond the Need to Boast: Cost Concealment Incentives and Exit in Cournot Duopoly

2009/31: Fellner G., Sausgruber R., Traxler C., Testing Enforcement Strategies in the Field: Legal Threat, Moral Appeal and Social Information

2009/30: Lüdemann J., Rechtsetzung und Interdisziplinarität in der Verwaltungsrechtswissenschaft forthcoming in: Öffentliches Recht und Wissenschaftstheorie, Tübingen, Mohr Siebeck, pp. 125-150, In Press.

2009/29: Engel C., Rockenbach B., We Are Not Alone: The Impact of Externalities on Public Good Provision

2009/28: Gizatulina A., Hellwig M., Informational Smallness and the Scope for Limiting Information Rents

2009/27: Hahmeier M., Prices versus Quantities in Electricity Generation

2009/26: Burhop C., The Transfer of Patents in Imperial Germany

2009/25: Burhop C., Lübbers T., The Historical Market for Technology Licenses: Chemicals, Pharmaceuticals, and Electrical Engineering in Imperial Germany

2009/24: Engel C., Competition as a Socially Desirable Dilemma Theory vs. Experimental Evidence

2009/23: Morell A., Glöckner A., Towfigh E., Sticky Rebates: Rollback Rebates Induce Non-Rational Loyalty in Consumers Experimental Evidence

2009/22: Traxler C., Majority Voting and the Welfare Implications of Tax Avoidance

2009/21: Beckenkamp M., Engel C., Glöckner A., Irlenbusch B., Hennig-Schmidt H., Kube S., Kurschilgen M., Morell A., Nicklisch A., Normann H., Towfigh E., Beware of Broken Windows! First Impressions in Public-good Experiments

2009/20: Nikiforakis N., Normann H., Wallace B., Asymmetric Enforcement of Cooperation in a Social Dilemma forthcoming in: Southern Economic Review, In Press.

2009/19: Magen S., Rechtliche und ökonomische Rationalität im Emissionshandelsrecht

2009/18: Broadberry S.N., Burhop C., Real Wages and Labour Productivity in Britain and Germany, 1871-1938: A Unified Approach to the International Comparison of Living Standards

2009/17: Glöckner A., Hodges S.D., Parallel Constraint Satisfaction in Memory-Based Decisions

2009/16: Petersen N., Review Essay: How Rational is International Law?

forthcoming in: European Journal of International Law, vol. 20, In Press.

2009/15: Bierbrauer F., On the legitimacy of coercion for the financing of public goods

2009/14: Feri F., Irlenbusch B., Sutter M., Efficiency Gains from Team-Based Coordination - Large-Scale Experimental Evidence

2009/13: Jansen J., On Competition and the Strategic Management of Intellectual Property in Oligopoly

2009/12: Hellwig M., Utilitarian Mechanism Design for an Excludable Public Good published in: Economic Theory, vol. 2009, no. July 14, Berlin/Heidelberg, Springer, 2009.

2009/11: Weinschenk P., Persistence of Monopoly and Research Specialization 
2009/10: Horstmann N., Ahlgrimm A., Glöckner A., How Distinct are Intuition and Deliberation? An Eye-Tracking Analysis of Instruction-Induced Decision Modes

2009/09: Lübbers T., Is Cartelisation Profitable? A Case Study of the Rhenish Westphalian Coal Syndicate, 1893-1913

2009/08: Glöckner A., Irlenbusch B., Kube S., Nicklisch A., Normann H., Leading with(out) Sacrifice?

A Public-Goods Experiment with a Super-Additive Player

forthcoming in: Economic Inquiry, In Press.

2009/07: von Weizsäcker C., Asymmetrie der Märkte und Wettbewerbsfreiheit

2009/06: Jansen J., Strategic Information Disclosure and Competition for an Imperfectly Protected Innovation forthcoming in: Journal of Industrial Economics, In Press.

2009/05: Petersen N., Abkehr von der internationalen Gemeinschaft? - Die aktuelle Rechtsprechung des US Supreme Court zur innerstaatlichen Wirkung von völkerrechtlichen Verträgen -

forthcoming in: Völkerrecht im innerstaatlichen Bereich, Vienna, facultas.wuv, In Press.

2009/04: Rincke J., Traxler C., Deterrence Through Word of Mouth

2009/03: Traxler C., Winter J., Survey Evidence on Conditional Norm Enforcement

2009/02: Herbig B., Glöckner A., Experts and Decision Making: First Steps Towards a Unifying Theory of Decision Making in Novices, Intermediates and Experts

2009/01: Beckenkamp M., Environmental dilemmas revisited: structural consequences from the angle of institutional ergonomics, issue 2009/01

\section{Preprints 2008}

2008/49: Glöckner A., Dickert S., Base-rate Respect by Intuition: Approximating Rational Choices in Base-rate Tasks with Multiple Cues

2008/48: Glöckner A., Moritz S., A Fine-grained Analysis of the Jumping to Conclusions Bias in Schizophrenia: DataGathering, Response Confidence, and Information Integration

2008/47: Hellwig M., A Generalization of the Atkinson-Stiglitz (1976) Theorem on the Undesirability of Nonuniform Excise Taxation

2008/46: Burhop C., The Underpricing of Initial Public Offerings in Imperial Germany, 1870-1896

forthcoming in: German Economic Review, In Press.

2008/45: Hellwig M., A Note on Deaton's Theorem on the Undesirability of Nonuniform Excise Taxation forthcoming in: Economics Letters, In Press.

2008/44: Hellwig M., Zur Problematik staatlicher Beschränkungen der Beteiligung und der Einflussnahme von Investoren bei großen Unternehmen

published in: Zeitschrift für das gesamte Handelsrecht und Wirtschaftsrecht, vol. 172, pp. 768-787, 2008.

2008/43: Hellwig M., Systemic Risk in the Financial Sector: An Analysis of the Subprime-Mortgage Financial Crisis published in: De Economist, no. 16.07.2009: Springer US, 2009.

published in: Jelle Zijlstra Lecture, no. 2008/5, Wassenaar, NL, Netherlands Institute for Advanced Study in the Humanities and Social Sciences, Institute of the Royal Netherlands Academy of Arts and Sciences, pp. 100, 2008.

2008/42: Glöckner A., Herbold A., Information Processing in Decisions under Risk: Evidence for Compensatory Strategies based on Automatic Processes 